\title{
How to Successfully Manage the School-to-Work Transition: \\ Integrating Job Search Quality in the Social Cognitive Model of Career Self- Management
}

\author{
Jolien Stremersch ${ }^{1}$, Greet Van Hoye ${ }^{1}$, and Edwin van Hooft $^{2}$ \\ ${ }^{1}$ Ghent University, Belgium \\ ${ }^{2}$ University of Amsterdam, The Netherlands
}

Citation: Stremersch, J., Van Hoye, G., \& van Hooft, E. A. J. (2021). How to successfully manage the school-to-work transition: Integrating job search quality in the social cognitive model of career self-management. Journal of Vocational Behavior, 131, 1-14. doi: https://doi.org/10.1016/j.jvb.2021.103643

This paper was partly funded by the Special Research Fund of the Ghent University under grant number BOF.STA.2015.0017.01. An early version of the paper was presented at the 34th Annual Society For Industrial and Organizational Psychology Conference, Washington, USA (April, 2019).

Correspondence concerning this article should be addressed to Jolien Stremersch, Department of Marketing, Innovation, and Organisation, Ghent University, Tweekerkenstraat 2, 9000 Ghent, Belgium. Email: jolien.stremersch@ugent.be 


\begin{abstract}
Over the past years, the school-to-work transition has become more volatile and complex, making it more important for graduates to take charge of their careers and to engage in selfregulatory activities. A central factor in successfully navigating this transition is job search. Integrating the social cognitive model of career self-management with recent theorizing on job search quality, we posit that a high-quality job search process (i.e., goal establishment, planning, goal striving, and reflection) will lead to key transition outcomes (i.e., job attainment and perceived fit) for graduates. We incorporate pre-, during, and post school-towork transition variables to provide new insights about proximal antecedents, processes, and outcomes of this transition. In our integrated model, we propose that job search quality is determined by graduates' job search self-efficacy, outcome expectations (i.e., perceived labor market demand), personality (i.e., conscientiousness), and context (i.e., social support). In turn, job search quality is expected to predict job attainment and perceived fit. The hypothesized model is tested in a sample of 255 Flemish graduates using a three-waved design. Results show that job search self-efficacy and conscientiousness related positively to most job search quality dimensions, and indirectly to job attainment. Goal establishment and goal striving positively predicted job attainment, whereas goal establishment was a significant predictor of perceived fit of the obtained job. These results can help graduates to conduct a higher-quality job search, and help career counselors to design more effective training programs.
\end{abstract}

Keywords: school-to-work transition, career self-management model, job search, job search quality, proximal antecedents, transition outcomes 


\section{How to Successfully Manage the School-to-Work Transition: Integrating Job Search Quality in the Social Cognitive Model of Career Self-Management}

Over the past years, the school-to-work transition has become more volatile and complex, making it harder for recent graduates to successfully transition to the labor market (Lechner et al., 2016). There are more career opportunities available than ever before, bringing about a number of potential career trajectories, but also uncertainty and higher risks (Akkermans et al., 2021; Brzinsky-Fay \& Solga, 2016). New labor market entrants often have limited knowledge about the possible job opportunities they could pursue, resulting in considerable ambiguity (Okay-Somerville \& Scholarios, 2021; Turban et al., 2009). In this complex career landscape, it has become increasingly important for graduates to take charge of their careers and to engage in self-regulatory activities, such as high-quality job search (Kanfer et al., 2001, Van Hooft et al., 2021; Wanberg et al., 2020).

The aim of the current study is to examine the role of job search quality, conceptualized as goal establishment, planning, goal striving, and reflection (cf. Van Hooft et al., 2013), in attaining desired transition outcomes (including both job attainment and perceived fit with the obtained job) during the school-to-work transition. We integrate job search quality into the social cognitive model of career self-management (CSM; Lent \& Brown, 2013), hereby also taking into account important proximal antecedents. According to the CSM model, job search self-efficacy, outcome expectations, supports and barriers encountered in the search process, and personality (i.e., conscientiousness; Lent \& Brown, 2013) will determine the extent to which graduates engage in goals and actions during their job search. In turn, these job search goals and actions will lead to desired transition outcomes. Although the model includes job search goals and actions, these do not fully grasp the selfregulatory activities that are needed during the increasingly complex and unpredictable school-to-work transition. In these circumstances, a high-quality job search is critical when 
making the school-to-work transition (Okay-Somerville \& Scholarios, 2021). This study uses a three-wave design incorporating pre-, during, and post school-to-work transition variables encompassing several months of the transition process.

The contributions of this study are threefold. First, we further contribute to research on job search during the school-to-work transition by acknowledging job search quality, beyond job search quantity (Okay-Somerville \& Scholarios, 2021). Because of the accelerating complexity and unpredictability of the labor market during the school-to-work transition, a self-regulated and high-quality job search is becoming indispensable for graduates (Van Hooft et al., 2013, 2021). Our study not only increases our understanding of the underlying job search mechanisms that lead to important job search outcomes in general, but especially during the school-to-work transition (Saks, 2018). Second, we address an important gap in social cognitive career theory (SCCT) by including job search quality in the CSM model. Job search is generally conceptualized as a self-regulated process that starts with the establishment of an employment goal, and involves planning, organizing, and implementing behaviors to attain a job (da Motta Veiga et al., 2018). However, past research on job search relying on SCCT or the CSM model has mostly focused on the intensity of job search, which may not be enough during the complex school-to-work transition (Lechner et al., 2016). An expansion of the CSM model to incorporate job search quality is critical to enhance the prediction of a successful school-to-work transition, and to provide guidance to job seeking graduates and career counseling professionals. Third, we aim to contribute to the job search and career development literatures, which have developed mostly independent from each other. By integrating insights from these two research streams we provide a more comprehensive understanding of the school-to-work transition process. Concretely, by integrating job search quality in the CSM model we enhance our understanding of the proximal antecedents and outcomes of the four job search quality dimensions. 


\section{Social Cognitive Model of Career Self-Management}

Originating from social cognitive career theory (SCCT; Lent et al., 1994), the social cognitive model of career self-management (CSM) was developed to explain career-related challenges and decisions of individuals across the lifespan (Lent \& Brown, 2013). The CSM model focusses on process rather than content aspects of career development (Brown \& Lent, 2019). In other words, rather than viewing the school-to-work transition as an isolated, delineated event that begins immediately before and ends immediately after graduation, the CSM conceptualizes the transition as a process that unfolds gradually throughout the school years and beyond. In this transition process, job search is one of the most important stages, because of its direct effects on the amount and quality of information job seekers obtain about job openings, the number of job opportunities, and in the end, transition outcomes such as the types of jobs and organizations in which graduates will obtain employment (Saks, 2018).

Because the CSM model builds on social cognitive theory (Bandura, 1986), it relies on many of the same core variables: The proximal antecedents self-efficacy beliefs, outcome expectations, personality, and environmental supports and barriers, and the process variables goals and actions. In the context of job search, self-efficacy refers to the belief that one is capable of organizing and executing job search behaviors (Saks et al., 2015). While selfefficacy refers to expectations about one's performance abilities, outcome expectations are beliefs about the consequences of performing certain behaviors or courses of action (Bandura, 1986). Like self-efficacy, positive outcome expectations stimulate approach behavior and persistence despite possible setbacks. For example, engaging in job search is enabled by confidence in one's ability to meet the requirements of potential employers (i.e., self-efficacy) as well as by optimistic beliefs about the outcomes that will result from the job search (i.e., outcome expectations). It is presumed that self-efficacy and outcome expectations influence goal-setting (Lent \& Brown, 2013). Goals help to organize and guide behavior, to sustain 
action over longer periods of time, and to increase the likelihood that desired outcomes will be attained. According to the CSM model, these core social cognitive constructs operate jointly with personality and contextual factors. Certain personality factors may influence how well-organized and persistent individuals are in their goal pursuit (e.g., conscientiousness). In addition, people are more likely to set goals and undertake action when they are supported by their environment (e.g., through social support) and are not hindered by contextual barriers.

Although prior research on the CSM model has identified job search as an important factor in the school-to-work transition (Kim et al., 2019; Lim et al., 2016), the model does not offer a clear understanding of what exactly happens during the job search process. In addition, although the CSM model proposes that job search is a goal-directed process, it has not often been empirically studied as such. Therefore, in the current study, we propose to integrate the CSM model with recent theorizing on a high-quality job search process in the job search literature to enhance our understanding of the specific job search dimensions that facilitate a successful school-to-work transition.

\section{Quality of the Job Search Process}

Based on a review and synthesis of the job search literature, Van Hooft et al. (2013) conceptualized a high-quality job search process as a multidimensional construct consisting of four dimensions: goal establishment, planning, goal striving, and reflection. Goal establishment involves setting clear and specific goals, as these help to organize and guide behavior, sustain behavior over longer periods of time, and increase the likelihood of attained desired outcomes (Lent et al., 1994; Latham et al., 2018). Empirical evidence supports this assumption, showing that setting clear goals for one's job search is related to more interviews, a higher chance for job attainment, and better employment quality (Côté et al., 2006;

Wanberg et al., 2002; Zikic \& Saks, 2009).

Planning refers to the consideration of steps towards reaching that goal (Van Hooft et 
al., 2013). Planning involves developing tactics and forming specific intentions that factor in reality considerations and require commitment (Lent et al., 1994). In a high-quality job search, job seekers need to specify the specific job search activities that they plan to perform (i.e., job search intentions; Van Hooft et al., 2004), as well as how, when, and where to search for a job (i.e., implementation intentions; Van Hooft et al., 2005). Specifying such intentions is a self-regulatory mechanism that facilitates the translation of cognitive plans into actual behavior (Van Hooft et al., 2005). Meta-analytic evidence supports the importance of job search intentions and implementation intentions for goal attainment (Gollwitzer \& Sheeran, 2006; Van Hooft et al., 2021). Proper planning should further include setting deadlines, as these induce motivation and lower procrastination (Ariely \& Wertenbroch, 2002).

Goal striving involves guarding the sustained performance of planned search behaviors. As there can be many obstacles and setbacks during job search, individuals need to manage their thoughts, attention, emotions, and motivation to control the search process (Wanberg et al., 2012). Baay et al. (2014) suggest that self-control is crucial during job search as it helps in establishing adaptive habits and routines. Another important self-regulatory mechanism to ensure goal striving is goal shielding, or keeping the job search goal in mind and ensuring that there are no distractions (Van Hooft et al., 2013).

While goal striving involves guarding the sustained job search activities, reflection involves the evaluation of these activities. During reflection, job seekers have to evaluate whether their goal striving was successful. They have to evaluate whether self-monitored information about the outcomes of the job search corresponds with the goals that they set (i.e., self-evaluation; Zimmerman, 2000). Reflection is a fundamental aspect for a high-quality job search because it facilitates learning from mistakes and it informs job seekers whether their goals, planning, or behavior should be adapted (Van Hooft et al., 2013). Research on this dimension in the job search literature is scarce, but there is some preliminary evidence for its 
importance (Wanberg et al., 2012).

Job seekers need to engage in all four of these dimensions to ensure a high-quality job search process. Although job seekers may vary on these dimensions at any point in time, we propose that all four dimension can be simultaneously relevant. This proposition aligns with Lord et al.'s (2010) assumption regarding self-regulation at an intermediate level around task or action goals. At this level, self-regulation may have a cycle time of a few minutes, hours, or days, as a goal is attempted and feedback is received. In theory, the four job search quality dimensions are succeeding each other rapidly and continuously. The pace at which this happens differs both across and within individuals. It is therefore impossible to measure the dimensions subsequently in the same cyclical fashion. For this reason, in the current study, we took a cross section of the dimensions at a given point in time.

Although there is a call for more attention to the quality of the job search process in the job search literature (e.g., Turban et al., 2009) and some research has started to examine quality-related components of job search (e.g., da Motta Veiga \& Turban, 2014; Koen et al., 2016), almost no research has investigated all four job search quality components conceptualized by Van Hooft et al. (2013). A notable exception is the study by Stremersch and Van Hoye (2020). However, the design of this study was cross-sectional, retrospective, and involved students looking for an internship, rather than graduates making the school-towork transition. In addition, we know little about the proximal antecedents of job search quality. Integrating job search quality in the CSM model enhances our understanding of both the proximal antecedents and outcomes of these specific job search quality dimensions.

As shown in Figure 1, in our integrative model, we propose that the extent to which recent graduates engage in goal establishment, planning, goal striving, and reflection in their job search is determined by their job search self-efficacy, outcome expectations (i.e., perceived labor market demand), and personality (i.e., conscientiousness), as well as by the 
context in which their job search occurs (i.e., social support). In turn, the four job search quality dimensions are expected to predict recent graduates' transition success (i.e., job attainment and perceived fit with the obtained job). In the next section we develop our specific hypotheses. On the basis of self-regulation theories and job search quality theorizing (Van Hooft et al., 2013), we expect all positive relationships between the job search quality dimensions and the proximal antecedents and transition outcomes. Although Van Hooft et al. (2013) state that all four dimensions are important in a high-quality job search process and are predicted by the same antecedents, we acknowledge that there might be differences in the strength of these relationships. Therefore, we will exploratively examine possible differences between the quality dimensions post hoc. Based on the findings of our study, we will take a first step towards theorizing about differences between the dimensions.

\section{Development of Hypotheses}

\section{Job Search Self-Efficacy}

According to the CSM model, job search self-efficacy has an important effect on many aspects in the job search process (Kim et al., 2019). For example, job search self-efficacy is expected to help determine whether people will approach or avoid job search activity, how persistent they will be in the face of challenge, and how well they will perform (Brown \& Lent, 2019; Sun et al., 2013). Individuals with high job search self-efficacy usually set challenging employment goals for themselves, are more firmly committed to their goals, and are less likely to give up when faced with difficulties or a prolonged search (Liu et al., 2014). In the context of job search among graduating students, previous research revealed that individuals with higher job search self-efficacy are more likely to set clear goals for their job search than individuals with lower job search self-efficacy (Côté et al., 2006). Based on these arguments, we propose that recent graduates' job search self-efficacy beliefs will relate positively to the four job search quality dimensions. 
H1: Job search self-efficacy will be positively related to (a) goal establishment, (b) planning, (c) goal striving, and (d) reflection.

\section{Outcome Expectations: Perceived Labor Market Demand}

The CSM model assumes that people are more likely to attempt and sustain behaviors when they have positive outcome expectations about these behaviors (Lent \& Brown, 2013). In a job search context, outcome expectations can be operationalized as perceived labor market demand (Van Hooft et al., 2021). Prior theorizing suggests that job seekers are more motivated to engage in job search when they have positive labor market demand perceptions (e.g., Leana \& Feldman, 1988). Along these lines, we propose that recent graduates who perceive that there are many job vacancies in their area of expertise will be more likely to believe that their job search will be successful and thus more likely to set goals, make plans, persist, and reflect in their job search. Job seekers who anticipate positive outcomes will put more care into their behaviors, less likely procrastinate their job search activities, and less likely give up when an obstacle or setback occurs.

H2: Perceived labor market demand will be positively related to (a) goal establishment, (b) planning, (c) goal striving, and (d) reflection.

\section{Personality: Conscientiousness}

This study focusses on conscientiousness as a personality factor in the CSM model for conceptual and empirical reasons. Conceptually, conscientiousness is defined by personal characteristics that are most likely to promote effective performance in achievement contexts (Lent \& Brown, 2013), such as being organized, planful, achievement-striving, and persistent (Digman, 1990). Empirically, meta-analytic evidence shows that the correlations of conscientiousness with indicators of job search self-regulation exceed the correlations of the other Big 5 personality traits with the same variables (Van Hooft et al., 2021). Therefore, we propose that conscientiousness positively relates to job search quality, as highly conscientious 
individuals are more likely to establish goals, plan, persist, and reflect until they achieve their goals (Barrick et al., 1993). Research on job search among recent graduates has shown that conscientiousness relates to setting clear job search goals (i.e., higher job search clarity; Côté et al., 2006) and more engagement in metacognitive activities (Turban et al., 2009).

H3: Conscientiousness will be positively related to (a) goal establishment, (b) planning, (c) goal striving, and (d) reflection.

\section{Contextual Factors: Social Support}

Finally, the CSM model distinguishes contextual factors such as social support as critical in affecting career behaviors. CSM posits that job seekers are more likely to set goals, implement actions, and behave adaptively when they are supported by their environment (Lent \& Brown, 2013). Especially for recent graduates, with little prior work experience or professional networks, social support can be particularly helpful (Zikic \& Klehe, 2006). Social support refers to the degree to which job seekers are provided with empathy, caring, love, and trust by their environment during job search. This support helps job seekers to manage their emotions during job search (i.e., emotional control; Wanberg et al., 2012) and increases their perceptions that trying to find a job is a worthwhile endeavor (Vinokur \& Caplan, 1987). Further, social support may buffer effects of social stressors, such as a job interview, on anxiety and irritation (Melloy et al., 2018). Therefore, we propose that recent graduates who feel more supported in their job search, will be more likely to establish employment goals, and engage in planning, goal striving and reflection.

H4: Social support will be positively related to (a) goal establishment, (b) planning, (c) goal striving, and (d) reflection.

\section{Transition Outcomes: Job Attainment and Perceived Fit}

The CSM model assumes that self-regulation affords people a measure of agency in their own career development (Brown \& Lent, 2019). Thus, favorable transition outcomes are 
facilitated by actively engaging in the job search process (Lim et al., 2016). Our hypothesized model proposes that job search quality will be positively related to both job attainment and perceived fit, which are key outcomes in the school-to-work transition (Saks, 2018).

Recent theorizing (e.g., Van Hooft et al., 2013; Van Hoye, 2018) has suggested that engaging in a high-quality job search process promotes the adjustment of behaviors and products (e.g., résumé, interview behavior) to the expectations of potential employers, resulting in a higher likelihood of attaining a job. Graduates with clearer job search goals have a better idea of the job they desire and aim their energy towards finding such a job (Côté et al., 2006). Planning links goals to behavioral tactics, and ensures that individuals prioritize and set deadlines (Lord et al., 2010), which is indispensable for a high-quality search process. Graduates who engage in planning, and thus specify and prioritize their job search activities to realize their goals, are better prepared to find a job (Saks \& Ashforth, 2002). Furthermore, graduates who implement self-regulatory behaviors during their job search, and shield their goal from distractions and setbacks, are more likely to attain a job (da Motta Veiga et al., 2018; Lent \& Brown, 2013). Finally, graduates who reflect upon their job search may be more likely to attain a job (Chawla et al., 2019; Turban et al., 2009). Reflection is crucial for a high-quality job search process, as it enables learning and gives information on which components of the process should be altered. Along these lines, research among recent graduates found that job search clarity and planning related positively to job attainment (Côté et al., 2006; Saks \& Ashforth, 2002).

H5: The job search quality dimensions (a) goal establishment, (b) planning, (c) goal striving, and (d) reflection will be positively related to job attainment.

According to the CSM model (Lent \& Brown, 2013) job search may not always result in fast and successful job attainment, and it is therefore preferable to consider adaptive job searching as a process that leads to a long-term outcome (Kim et al., 2013; Lent \& Brown, 
2013). In this regard, our model includes finding a fitting job after graduation as a more sustainable and long-term outcome. Establishing a clear job search goal will increase selfawareness and decision-making during the job search process (Zimmerman, 2000), leading to better fitting job opportunities. In addition, planning may enable recent graduates to identify jobs and organizations that they want and perceive to be a good fit (Saks \& Ashforth, 2002). Furthermore, graduates who keep their goals in mind and are persistent during their goal striving are more likely to find a better fitting job (Lent \& Brown, 2013). Finally, recent graduates who reflect upon their job search may be more likely to discover what employers are looking for, to improve their job search behavior, and finally, to find a fitting job opportunity (Van Hooft et al., 2013). In line with these theoretical assumptions, Wanberg and colleagues (2002) showed that having clearer job search goals was related to higher levels of perceived fit in a sample of unemployed job seekers. Other research found that career planning during the school-to-work transition related positively to person-job fit of the new job (Saks \& Ashforth, 2002). Finally, research on the four job search quality dimensions among students looking for an internship showed that reflection was an important correlate of perceived fit (Stremersch \& Van Hoye, 2020).

H6: The job search quality dimensions (a) goal establishment, (b) planning, (c) goal striving, and (d) reflection will be positively related to perceived fit.

Finally, previous research on career transitions (e.g., Pinquart et al., 2003; van der Horst et al., 2017) and job search (Kanfer et al., 2001; Van Hooft et al., 2021) suggests that antecedents such as self-efficacy, labor market demand, conscientiousness, and social support positively relate to transition outcomes. However, self-regulatory job search models (Kanfer et al., 2001; Van Hooft et al., 2021) suggest that such variables mostly exert their influence on transition outcomes through motivational and self-regulatory processes. We therefore expect: H7: The proximal antecedents (job search self-efficacy, perceived labor market 
demand, conscientiousness, social support) will have a positive indirect effect on the transition outcomes (job attainment and perceived fit) through job search quality (goal establishment, planning, goal striving, and reflection).

\section{Method}

\section{Procedure}

The data for this study were collected in Flanders (i.e., the Dutch-speaking part of Belgium). In 2018, the general unemployment rate on the Flemish labor market was $6.3 \%$, and among recent graduates the unemployment rate was 3.1\% (VDAB, 2020). The data collection started around one of the most important career fairs in Flanders, providing the start of most new labor market entrants' job search. The proximal antecedents (i.e., job search selfefficacy, perceived labor market demand, conscientiousness, social support) were assessed at Time 1 two months before students' planned graduation (May 2018), job search quality at Time 2 one month after graduation (August 2018), and the transition outcome variables at Time 3 four months after graduation (November 2018). This design of the measurement times allowed us to temporally separate antecedents, job search quality dimensions, and outcomes, and to space these variables according to the school-to-work transition and job search process.

Participants were recruited at Time 1 via the newsletter of the career fair, via student administration offices, and through social media. They were asked to fill in an online survey as part of a study designed to better understand how graduates find jobs. After completion, we asked participants to leave their email address if they would like to participate in the followup studies. It was made clear that all responses would be treated anonymously, that their email address would only be used to link the responses, that answers would be used for research purposes only, and that they should answer honestly based on their experiences. To enhance our response rate, participants could win one out of ten $€ 50$,- gift cards if they completed all three online surveys. The ethics committee of the first two authors' university 
approved this study and the procedure followed.

\section{Participants}

Our sample consisted of graduating final-year students from different Flemish universities and vocational colleges. To be included in the study, participants were required to graduate at the end of the school year, to be looking for a job at Time 1 or in the next six months, and to not have found a job at Time 1. Our raw data file consisted of 834 respondents. On the basis of the aforementioned criteria, 172 of the 834 respondents were excluded, resulting in a total of 662 respondents. Of these, 425 left their email address for the follow-up measurements. Three months after the first wave, we sent the second survey to these 425 respondents. Of these, 303 respondents filled out the second survey, yielding a response rate of $71.3 \%$. Another three months later, the third survey was sent to the Time 2 ( $N$ $=303)$ respondents, this time yielding a response rate of $84 \%(N=255)$. Participants were only included in the analyses if they had completed all three questionnaires.

Of our sample of 255 respondents, the average age was 23 years $(S D=2.12)$, and $77.6 \%$ were women. Regarding education, $72.2 \%$ of our sample was graduating at a university and $27.8 \%$ was graduating at a vocational college. University graduates were mostly arts, humanities and social sciences graduates, majoring in Economics (23.2\%), Psychology (17.4\%), or Business Administration (16.8\%). Vocational college graduates were mostly majoring in Social work (25.5\%), Healthcare (23.6\%), or Business Administration (21.8\%). At Time 3, 76.9\% of our sample had found a job.

To check for selective nonresponse, the respondents who participated at Time 1 only were compared with the respondents who participated in all three waves. Some nonrandom attrition was observed, $\chi 2(8)=28.95, p<.01$. Specifically, women $(\operatorname{Exp}[B]=2.34, p=.001)$ and university graduates $(\operatorname{Exp}[B]=1.90, p=.003)$ were more likely to remain in the study.

\section{Time 1 Measures}


Items were rated on a 5-point scale ranging from $1=$ completely disagree to $5=$ completely agree, unless stated otherwise.

Job search self-efficacy. Using Van Ryn and Vinokur's (1992) six-item measure, participants indicated their confidence in successfully performing six job search tasks on a 5point rating scale $(1=$ not at all confident to $5=$ a great deal confident $)$. A sample item is: "Make the best impression and get points across in an interview" $(\alpha=.82)$.

Perceived labor market demand. Three items based on Wanberg et al. (2002) were used to measure perceived labor market demand. A sample item is "There are a lot of vacancies in my field of expertise" $(\alpha=.87)$.

Conscientiousness. Similar to previous studies (e.g., Côté et al., 2006), we measured conscientiousness with a ten-item scale from the International Personality Item Pool (2001; e.g., "I am always well prepared"; $\alpha=.83$ ), corresponding to the broad conscientiousness domain of the Revised NEO Personality Inventory (NEO-PI-R; Costa \& McCrae, 1995).

Social support. Social support was measured with a three-item measure based on House (1981). A sample item is "There are people around me (e.g., partner, friends, family) who I can count on to encourage my efforts to find a job" $(\alpha=.84)$.

Control variables. We controlled for sex $(0=$ male, $1=$ female $)$, age, and education $(0=$ vocational college, $1=$ university $)$ in the prediction of job attainment and perceived fit, because these variables may relate to transition outcomes (Kanfer et al., 2001).

\section{Time 2 Measures}

Job search quality. Job search quality was measured using a 16-item scale adapted from Stremersch and Van Hoye (2020; note that we had early access to this measure). Participants were asked to what extent they engaged in goal establishment, planning, goal striving, and reflection in the last three months, or up until the moment they had found a job. All items were adapted to a graduate job search context. In addition, as suggested by 
Stremersch and Van Hoye (2020), we aimed to improve their measure by replacing items with a low factor loading and extending each scale with an additional item. ${ }^{1}$ Confirmatory factor analyses showed that the expected four-factor model provided a good fit with the data, $\chi^{2}(98)$ $=160.52, p<.001, \mathrm{CFI}=.96, \mathrm{RMSEA}=.05, \mathrm{SRMR}=.05$. The four-factor model fit the data significantly better than a model in which all items loaded on a single global job search quality factor, $\Delta \chi^{2}(6)=397.07, p<.001$, as this one-factor model produced a poor fit, $\chi^{2}(104)$ $=557.59, p<.001, \mathrm{CFI}=.67, \mathrm{RMSEA}=.13, \mathrm{SRMR}=.09$. All items and their standardized factor loadings from the four-factor model can be found in Table 1. The internal consistency coefficient $\alpha$ was satisfactory for all four dimensions: goal establishment $(\alpha=.83)$, planning $(\alpha=.79)$, goal striving $(\alpha=.88)$, and reflection $(\alpha=.86)$.

\section{Time 3 Measures}

Job attainment. We measured job attainment by asking respondents if they had found a job in the past six months $(0=n o, 1=y e s)$.

Perceived fit. We used a three-item measure based on Wanberg et al. (2002) that asked respondents to what extent their job measured up to the type of job they were looking for. A sample item is "My new job measures up to the kind of job I was seeking" $(\alpha=.80)$.

\section{Results}

Table 2 presents all means, standard deviations, and correlations. We tested our hypotheses with observed variable path analysis using maximum likelihood estimation with the Lavaan package in R (Rosseel, 2012). Hu and Bentler (1999) recommend values close to .95 for the comparative fit index (CFI), values close to .06 for the root mean square error of approximation (RMSEA), and values close to .08 for the standardized rout mean squared residual (SRMR) as indicative of a good fit. We could not include job attainment and perceived fit in the same path model because perceived fit could only be reported by recent

\footnotetext{
${ }^{1}$ For more information on scale development, please contact the corresponding author.
} 
graduates who obtained a job. Therefore, we tested our hypothesized model shown in Figure 1 separately for each outcome. Because of the smaller $(N=196)$ and more selective sample for perceived fit (including only those who found a job), we tested the study's hypotheses concerning the proximal antecedents (H1-4) in the first model for job attainment, including our entire sample $(N=255)$. Additionally, we tested two alternative path models that added direct paths from the proximal antecedents to the respective outcome. In all four models, we controlled for age, sex, and education, but none of these relationships were significant.

\section{Path Model Job Attainment}

For job attainment, the fit indices show that overall our hypothesized model provided a satisfactory fit to the data, $\chi^{2}(28)=72.94, p<.01, \mathrm{CFI}=.93, \mathrm{RMSEA}=.08, \mathrm{SRMR}=.06$. Next, we inspected the standardized path coefficients for the hypothesized relationships (see Figure 2). With respect to the proximal antecedents of graduates' job search process, job search self-efficacy was significantly related to all four job search quality dimensions in the expected direction. Recent graduates with higher job search self-efficacy beliefs were more likely to engage in goal establishment $(\beta=.20, p=.003)$, planning $(\beta=.17, p=.01)$, goal striving $(\beta=.14, p=.03)$, and reflection $(\beta=.19, p=.003)$, supporting Hypotheses 1a-d. Second, none of the paths between perceived labor market demand and the job search quality dimensions were significant (H2a-d not supported). Third, recent graduates higher in conscientiousness displayed more goal establishment $(\beta=.16, p=.02)$, planning $(\beta=.15, p=$ $.03)$, and goal striving $(\beta=.23, p<.001)$, supporting Hypotheses $3 \mathrm{a}, \mathrm{b}$, and $\mathrm{c}$, but not

Hypothesis $3 \mathrm{~d}$. Fourth, the paths between social support and goal establishment, planning, and goal striving were not significant (H4a-c not supported). However, in support of Hypothesis $4 \mathrm{~d}$, social support was positively related to reflection $(\beta=.14, p=.03)$.

Further, two of the job search quality dimensions significantly predicted job attainment. Specifically, recent graduates who engaged more in goal establishment $(\beta=0.21$, 
$p=.006)$ and goal striving $(\beta=0.41, p<.001)$ were more likely to find a job, supporting Hypotheses 5a and c. Although planning and reflection were positively correlated with job attainment, they did not predict unique variance in job attainment when controlling for the other job search quality dimensions. Therefore, Hypotheses $5 \mathrm{~b}$ and $\mathrm{d}$ were not supported.

Next, we tested whether the proximal antecedents indirectly related to job attainment through the job search quality dimensions (Hypothesis 7). We estimated these indirect effects using the SEM function in Lavaan (Rosseel, 2012) and used 5,000 bootstraps to estimate their 95\% confidence intervals. In line with the significant relationships reported above, we observed a positive indirect effect of job search self-efficacy on job attainment through goal establishment $(\beta=.04,95 \%$ CI $[.003, .05])$ and goal striving $(\beta=.06,95 \%$ CI $[.001, .07])$. We also observed a positive indirect effect of conscientiousness on job attainment through goal establishment $(\beta=.03,95 \% \mathrm{CI}[.001, .06])$ and goal striving $(\beta=.10,95 \% \mathrm{CI}[.02, .13])$.

Finally, we compared the proposed model to an alternative model with direct paths from all proximal antecedents to job attainment. The fit of the alternative model, $\chi^{2}(24)=$ $70.34, p<.001, \mathrm{CFI}=.93, \mathrm{RMSEA}=.09, \mathrm{SRMR}=.06$, did not significantly differ from the hypothesized model, $\Delta \chi^{2}(4)=2.60, p=.63$. None of the direct paths of the proximal antecedents to job attainment were significant.

\section{Path Model Perceived Fit}

For perceived fit, the model fit indices show that overall the hypothesized model provided a satisfactory fit to the data, $\chi^{2}(28)=61.48, p<.001, \mathrm{CFI}=.90, \mathrm{RMSEA}=.08$, $\mathrm{SRMR}=.06$. In this smaller and more selective sample, less significant relationships between the proximal antecedents and the job search quality dimensions were observed (see Figure 3). Conscientiousness $(\beta=.19, p=.008)$ emerged as a predictor of goal striving, and social support $(\beta=.15, p=.04)$ predicted reflection. Further, recent graduates who engaged more in goal establishment experienced a better fit with their obtained job $(\beta=0.22, p=.008)$, 
supporting Hypothesis 6a. None of the other job search quality dimensions were significantly related to perceived fit (H6b-d not supported).

Lastly, we tested whether the proximal antecedents indirectly related to perceived fit through the job search quality dimensions (Hypothesis 7). We estimated these indirect effects in our path model and used 5,000 bootstraps to estimate their 95\% confidence intervals.

However, as none of the proximal antecedents significantly predicted goal establishment and only goal establishment predicted perceived fit, no significant indirect effects were observed. Finally, we compared the proposed model to an alternative model with direct paths from all proximal antecedents to perceived fit. The fit of the alternative model, $\chi^{2}(24)=54.52, p<$ $.001, \mathrm{CFI}=.90, \mathrm{RMSEA}=.08, \mathrm{SRMR}=.06$, did not significantly differ from the fit of the hypothesized model, $\Delta \chi^{2}(4)=6.95, p=.14$. None of the direct paths of the proximal antecedents to perceived fit were significant.

\section{Discussion}

The school-to-work transition has become increasingly volatile and complex, suggesting the need for a high-quality, self-regulatory approach towards job seeking. In order to better understand the school-to-work transition, it is crucial to integrate both the job search and the career development literatures. In the current study, we integrated job search quality in the social cognitive model of career self-management (CSM; Lent \& Brown, 2013), uncovering the underlying job search quality process mechanisms that explain how proximal antecedents influence transition outcomes during the school-to-work transition.

Our study makes three main contributions to the scholarly literature. First, we found that job search quality is an important predictor of job attainment and perceived fit during the school-to-work transition. Our results showed that recent graduates who engaged more in high-quality goal establishment and goal striving during their job search had a higher chance of finding a job, and those who engaged more in high-quality goal establishment reported 
greater fit with the obtained job. It is also worth noting that while goal establishment had a small-medium effect size in predicting job attainment, goal striving displayed a mediumstrong effect size. The results highlight the necessity to take job search quality into account when studying the school-to-work transition, as self-regulatory job search activities are highly needed during this transition (Okay-Somerville \& Scholarios, 2021). Our study hereby further underlines the potential in integrating the job search and career transitions literature in future research. Further, expanding the CSM model (Lent \& Brown, 2013) to incorporate job search quality is relatively new in studies on the school-to-work transition and we encourage future research to continue to include job search quality into the CSM model.

Second, although theory suggests that all four dimensions are theorized to be important for predicting employment success (Van Hooft et al., 2013), our findings showed that the different dimensions of job search quality were not equally important predictors of transition outcomes. Some dimensions are probably important in all contexts (i.e., goal establishment and goal striving), but the importance of other dimensions might depend on the type of sample and their chances on the labor market. These results add to preliminary findings by Stremersch and Van Hoye (2020), who found that reflection related to higher fit perceptions in an internship context, and that planning related to the speed with which an internship was found. Interestingly, we did not find support for planning and reflection in predicting unique variance in transition outcomes. These findings may suggest that reflection may be more important in a context that requires learning, for example an internship context (cf. Stremersch \& Van Hoye, 2020). Perhaps the lack of a positive relationship between reflection and the transition outcomes in our study is the result of the low quality (or even absence of) feedback that graduates receive from organizations when applying for jobs (Chawla et al., 2019). The mean of reflection is not necessarily lower than the other dimensions, indicating that graduates have in fact reflected on their job search. However, it is 
possible that they did not receive enough information on how their performance can be improved. Alternatively, reflection may have been found less necessary by our participants because of the favorable labor market at the time of our study (i.e., 77\% of participants had found a job at Time 3). Planning may be more important when there are more conflicting tasks during job search and a good preparation is indispensable. Even though we had a successful sample in our study, we want to stress that this does not mean that job search quality is less important in a favorable labor market. While it is possible that the importance of specific job search quality dimensions for finding a job may vary depending on the chances on the labor market, this might not be the case for longer-term employment quality and career outcomes. Future longitudinal studies incorporating samples with different labor market prospects are needed to test these hypotheses. Altogether, these divergent findings for the different dimensions support the use of a multidimensional conceptualization of job search quality (Van Hooft et al., 2013) rather than a global measure (Turban et al., 2009). We encourage future research to not only include job search quality, but to also include the different dimensions (Van Hooft et al, 2013).

Our third contribution pertains to the role of proximal antecedents predicting job search quality during the school-to-work transition. We extend previous models on job search quality (Van Hooft et al., 2013), by identifying to what extent individual differences and situational factors are of importance for the development of each dimension of job search quality. Job search self-efficacy was positively related to all four dimensions of job search quality, and indirectly related to job attainment through goal establishment and goal striving. These findings also contribute to research on the CSM model (Lent \& Brown, 2013) by identifying the underlying job search quality mechanisms that explain how job search selfefficacy relates to transition outcomes during the school-to-work transition. To our surprise, perceived labor market demand did not relate to any of the four job search quality dimensions. 
A possible explanation for these findings can be found in control theory (Klein, 1989) and economic rational choice theory (McFadyen \& Thomas, 1997), which suggest that recent graduates who hold positive labor market demand perceptions might invest less in job search because they perceive less deliberate and high-quality effort is needed to obtain transition success. It might be that a high perceived labor market demand has both positive and negative effects during the school-to-work transition, resulting in a null effect. Future research might delve deeper into these mechanisms. Further, it is possible that perceived labor market demand might be more beneficial for goal establishment, but less beneficial for goal striving. However, we were not able to detect this in our results. Lastly, it is possible that graduates simply do not have enough knowledge about the labor market to self-report whether there are a lot of vacancies for someone with their competencies. We encourage future research to take into account a more objective measure of labor market demand (e.g., number of open vacancies in that field of work). Our results extend previous research that states that personality factors can facilitate the use of behaviors that require planning and persistence, by shedding new light on how personality facilitates the job search process during the school-towork transition. This is especially true for conscientiousness that involves traits most likely to promote effective performance (Côté et al., 2006; Lent \& Brown, 2013). Graduates higher in conscientiousness are not only more likely to establish goals for their job search, but also more likely to persist until they achieve their goals.

Support for the role of contextual factors was limited in our study. Most of the relationships between social support and job search quality were not significant, and no indirect effects on the transition outcomes were found. These results could be due to the favorable labor market position of our sample (i.e., low unemployment rate), whereas social support may be more important when it is harder to find a job. We did find that social support was positively related to reflection. Graduates who perceive greater social support likely talk 
more to others about their pursuit for a job, which might help them with reflecting upon their job search. This shows that contextual factors can help shape learning experiences (i.e., reflection) that fuel career choices (Lent \& Brown, 2013).

\section{Limitations and Future Research Directions}

The current study has some limitations that need to be noted. First, this study only took into account the first few months before and after graduation. Although job attainment and perceived fit about four months after graduation do give an idea about the first job graduates land, this is not enough to capture the complete transition process from school to work (Brzinsky-Fay, 2014). For instance, it might be possible that other dimensions of job search quality are important in predicting employment outcomes in the long run. We suggest that future research includes a longer time span, by including more measures before graduation (cf. Grosemans \& De Cuyper, 2021), to determine how previous phases in career development influence the job search process. For example, it would be of interest to examine how important career-related constructs such as career competencies (Akkermans et al., 2013) and career adaptability (Savickas \& Porfeli, 2012) influence job search quality during the school-to-work transition. Another suggestion would be to follow individuals for a longer duration after graduation (i.e., a few years after leaving school; Brzinsky-Fay \& Solga, 2016) to examine if and how job search quality affects career development in the longer run. In this regard, we hope that future research will continue the fruitful integration of the job search and career development literatures.

A second issue is that the proximal antecedents in our model are all facilitators for the job search process and school-to-work transition. Although the CSM model posits that both contextual supports and contextual barriers affect goals, we only included a contextual support measure (i.e., social support). We encourage future research to investigate barriers that hinder job search quality among graduates, and thus hamper the transition from school to 
work. For example, future research could include a comprehensive measure of global barriers, such as the Career Barriers Inventory-Revised (Swanson et al., 1996), designed to measure perceived barriers for career progress: gender and racial discrimination, peer disapproval, being discouraged from choosing non-traditional careers, job market constraints, and difficulties with networking.

A third issue concerns our measure of perceived fit. Although we included an existing fit measure that is common and accepted in the domain of job search (Wanberg et al., 2002), this measure deserves closer examination. Respondents were asked to what extent their job expectations are fulfilled, which relates to the job search goals they had set. This might be an alternative explanation for the positive relationship between goal establishment and perceived fit we observed. Note however that Stremersch and Van Hoye (2020) used a similar measure of perceived fit and observed a positive relation with reflection, not goal establishment. Future research should look at other fit measures that are less focused on job search goals, such as needs-supplies fit, person-organization fit, or demands-abilities fit (Cable \& Derue, 2002). In addition, other transition outcomes should be examined such as job satisfaction.

Fourth, Van Hooft et al. (2013) proposed that a high-quality job search is characterized by engaging in all four dimensions of job search quality. After graduates have evaluated their job search process, they might adjust their goals or change their planning if they realize that the current approach is not producing the desired results. As a result, the cycle might have to be completed several times before they reach their goal. In this study, our focus was on investigating the proximal antecedents and outcomes of the school-to-work transition. Job search quality was only measured at one point in time, thus, it was not possible to investigate such changes in job search quality. Understanding these dynamic aspects would represent an intriguing avenue for future research. We need to know how each dimension affects the other, and how the same dimensions evolve across time, using a within-person 
perspective (da Motta Veiga \& Gabriel, 2016). To this end, graduates should be monitored more closely as they progress in their job search (i.e., with a weekly cross-lagged design).

Finally, although we aimed to recruit participants who were more or less in the same stage of their job search, we did not explicitly measure job search duration in our sample to verify this. It is therefore possible that some graduates were at different stages in their job search at the start of the study. However, a recent meta-analysis (Van Hooft et al., 2021) found no significant relationships between job search duration and job search self-regulation, job search intensity, employment status, and employment quality (all credibility intervals contained 0). Nonetheless, future research should take this into account and control for how far along the process job seekers are.

\section{Practical Implications}

In sum, job search quality can help graduates navigate in an increasingly complex and unpredictable labor market landscape. We hope that our study encourages practitioners to use the results in helping graduates make the school-to-work transition, in order to boost job search quality and employment outcomes. First, our findings show that graduates with lower levels of job search self-efficacy and conscientiousness tend to engage less in goal establishment and have difficulty to maintain goal striving. Because these dimensions are important for a successful school-to-work transition, it is important that graduates are aware of how they score on these variables. Career centers could provide self-assessments with automated feedback to graduates to increase their awareness. Graduates scoring low can be offered more specific feedback and guidance on how to increase job search quality.

Second, given the importance and malleability of job search self-efficacy, graduates (especially those scoring low on a self-assessment questionnaire) could be encouraged to follow a specific training program to help boost their job search self-efficacy. According to social cognitive theory (Bandura, 1986, 1991) there are a few sources of individuals' self- 
efficacy: Vicarious learning through observing others, being verbally persuaded that they can do it, and practicing to obtain success experiences. Accordingly, learning job seeking through observation and practicing effective job search behaviors might boost job search self-efficacy. For example, a training on job search self-efficacy could include showing video clips with models performing successful job search behaviors (i.e., observing), followed by a brief discussion and role-playing in small groups (i.e., practicing). The encouragement of the trainer and fellow graduates could provide verbal persuasion (Eden \& Aviram, 1993).

Finally, career counselors could offer training programs at career fairs that specifically target goal establishment and goal striving in addition to existing, more global workshops (e.g., job application training). Because career fairs provide the start of most new labor market entrants' job search, it is the ideal time to learn and immediately implement new techniques to kick start their career. These programs should include exercises to teach recent graduates how to set effective job search goals (e.g., clear, specific, proximal, publicly stated) that are most likely to be implemented and sustained over time (Bandura, 1986). In addition, techniques to persevere and not be distracted during goal striving should also be included (e.g., bolstering the value of job attainment, formation of goal-shielding implementation intentions; Van Hooft et al., 2013). 


\section{References}

Akkermans, J., Blokker, R., Buers, C., Van der Heijden, B., \& De Vos, A. (2021). Ready, Set, Go! In E. A. Marshall \& J. E. Symonds (Eds.), Young Adult Development at the School-to-Work Transition (pp. 77-103). Oxford University Press.

Akkermans, J., Brenninkmeijer, V., Huibers, M., \& Blonk, R. W. B. (2013). Competencies for the contemporary career: Development and preliminary validation of the career competencies questionnaire. Journal of Career Development, 40, 245-267. https://doi.org/10.1177/0894845312467501

Ariely, D., \& Wertenbroch, K. (2002). Procrastination, deadlines, and performance: Selfcontrol by precommitment. Psychological Science, 13, 219-224. https://doi.org/10.1111/1467-9280.00441

Baay, P. E., de Ridder, D. T. D., Eccles, J. S., van der Lippe, T., \& van Aken, M. A. G. (2014). Self-control trumps work motivation in predicting job search behavior. Journal of Vocational Behavior, 85, 443-451.https://doi.org/10.1016/j.jvb.2014.09.006

Bandura, A. (1986). Social foundations of thought and action: A social cognitive theory. Englewood Cliffs, NJ: Prentice Hall.

Bandura, A. (1991). Social cognitive theory of self-regulation. Organizational Behavior and Human Decision Processes, 50, 248-287. https://doi.org/10.1016/07495978(91)90022-L

Barrick, M. R., Mount, M. K., \& Strauss, J. P. (1993). Conscientiousness and performance of sales representatives: Test of the mediating effects of goal setting. Journal of Applied Psychology, 78, 715-722. https://doi.org/10.1037/0021-9010.78.5.715

Brown, S. D., \& Lent, R. W. (2019). Social cognitive career theory at 25: Progress in studying the domain satisfaction and career self-management models. Journal of Career Assessment, 27, 563-578. https://doi.org/10.1177/1069072719852736 
Brzinsky-Fay, C. (2014) The measurement of school-to-work transitions as processes: About events and sequences. European Societies, 16, 213-232.

https://doi.org/10.1080/14616696.2013.821620

Brzinsky- Fay, C., \& Solga, H. (2016). Compressed, postponed, or disadvantaged? Schoolto-work-transition patterns and early occupational attainment in West Germany. Research in Social Stratification and Mobility, 46, 21-36. https://doi.org/10.1016/ j.rssm.2016.01.004

Cable, D. M., \& DeRue, D. S. (2002). The convergent and discriminant validity of subjective fit perceptions. Journal of Applied Psychology, 87, 875-884. https://doi.org/10.1037/0021-9010.87.5.875

Chawla, N., Gabriel, A. S., \& da Motta Veiga, S. P., \& Slaughter, J. E. (2019). Does feedback matter for job search self-regulation? It depends on feedback quality. Personnel Psychology, 72, 513-541. https://doi.org/10.1111/peps.12320

Costa, P. T., \& McCrae, R. R. (1995). Domains and facets: Hierarchical personality assessment using the Revised NEO Personality Inventory. Journal of Personality Assessment, 64, 21-50. https://doi.org/10.1207/s15327752jpa6401_2

Côté, S., Saks, A. M., \& Zikic, J. (2006). Trait affect and job search outcomes. Journal of Vocational Behavior, 68, 233-252. https://doi.org/10.1016/j.jvb.2005.08.001

da Motta Veiga, S. P., \& Turban, D. B. (2014). Are affect and perceived stress detrimental or beneficial to job seekers? The role of learning goal orientation in job search selfregulation. Organizational Behavior and Human Decision Processes, 125, 193203.https://doi.org/10.1016/j.obhdp.2014.09.007

da Motta Veiga, S. P., \& Gabriel, A. S. (2016). The role of self-determined motivation in job search: A dynamic approach. Journal of Applied Psychology, 101, 350-361. https://doi.org/10.1037/ap10000070 
da Motta Veiga, S. P., Turban, D. B., Gabriel, A. S., Chawla, N. (2018). From the unfolding process to self-regulation in job search: integrating between-and within-person approaches. Research in Personnel and Human Resource Management, 36, 243-74. https://doi.org/10.1108/S0742-730120180000036007

Digman, J. M. (1990). Personality structure: Emergence of the five-factor model. Annual Review of Psychology, 41, 417-440. https://doi.org/10.1146/annurev.ps.41.020190.002221

Eden, D., \& Aviram, A. (1993). Self-efficacy training to speed reemployment: Helping people to help themselves. Journal of Applied Psychology, 78, 352-360. https://doi.org/10.1037/0021-9010.78.3.352

Gollwitzer, P. M., \& Sheeran, P. (2006). Implementation intentions and goal achievement: A meta-analysis of effects and processes. Advances in Experimental Social Psychology, 38, 69-119. https://doi.org/10.1016/S0065-2601(06)38002-1

Grosemans, I., \& De Cuyper, N. (2021). Career competencies in the transition from higher education to the labor market: Examining developmental trajectories. Journal of Vocational Behavior, 128, Article 103602. https://doi.org/10.1016/j.jvb.2021.103602

House, J. S. (1981). Work stress and social support. Reading, Mass: Addison-Wesley.

Hu, L.-t., \& Bentler, P. M. (1999). Cutoff criteria for fit indexes in covariance structure analysis: Conventional criteria versus new alternatives. Structural Equation Modeling, 6, 1-55. https://doi.org/10.1080/10705519909540118

International Personality Item Pool (2001). A scientific collaboratory for the development of advanced measures of personality traits and other individual differences. Retrieved from http://ipip.ori.org/

Kanfer, R., Wanberg, C. R., \& Kantrowitz, T. M. (2001). Job search and employment: A personality-motivational analysis and meta-analytic review. Journal of Applied 
Psychology, 86, 837-855. https://doi.org/10.1037/0021-9010.86.5.837

Kim, J. G., Kim, H. J., \& Lee, K. H. (2019). Understanding behavioral job search selfefficacy through the social cognitive lens: A meta-analytic review. Journal of Vocational Behavior, 112, 17-34. https://doi.org/10.1016/j.jvb.2019.01.004

Koen, J., van Vianen, A. E. M., Van Hooft, E. A. J., \& Klehe, U. C. (2016). How experienced autonomy can improve job seekers' motivation, job search, and chance of finding reemployment. Journal of Vocational Behavior, 95-96, 31-44. https://doi.org/10.1016/j.jvb.2016.07.003

Klein, H. J. (1989). An integrated control theory model of work motivation. Academy of Management Review, 14, 150-172. http://dx.doi.org/10.5465/amr.1989.4282072 Latham, G. P., Mawritz, M. B., \& Locke, E. A. (2018). Goal setting and control theory: Implications for job search. In U. C. Klehe \& E. A. J. Van Hooft (Eds.), The Oxford handbook of job loss and job search (pp. 129-142). Oxford University Press.

Leana, C. R., \& Feldman, D. C. (1988). Individual responses to job loss: Perceptions, reactions, and coping behaviors. Journal of Management, 14, 375-389. https://doi.org/10.1177/014920638801400302

Lechner, C. M., Tomasik, M. J., \& Silbereisen, R. K. (2016). Preparing for uncertain careers: How youth deal with growing occupational uncertainties before the education-to-work transition. Journal of Vocational Behavior, 95, 90-101. https://doi.org/10.1016/j.jvb.2016.08.002

Lent, R. W., \& Brown, S. D. (2013). Social cognitive model of career self-management: Toward a unifying view of adaptive career behavior across the life span. Journal of Counseling Psychology, 60, 557-568. https://doi.org/10.1037/a0033446

Lent, R. W., Brown, S., \& Hackett, G. (1994). Toward a unifying social cognitive theory of career and academic interest, choice, and performance. Journal of Vocational 
Behavior, 45, 79-122. https://doi.org/10.1006/jvbe.1994.1027

Lim, R. H., Lent, R. W., \& Penn, L. T. (2016). Prediction of job search intentions and behaviors: Testing the social cognitive model of career self-management. Journal of Counseling Psychology, 5, 594-603. https://doi.org/10.1037/cou0000154

Liu, S., Wang, M., Liao, H., \& Shi, J. (2014). Self-regulation during job search: The opposing effects of employment self-efficacy and job search behavior self-efficacy. Journal of Applied Psychology, 1159-1172. https://doi.org/10.1037/a0036692

Lord, R. G., Diefendorff, J. M., Schmidt, A. M., \& Hall, R. J. (2010). Self-regulation at work. Annual Review of Psychology, 61, 543-568. https://doi.org/10.1146/annurev.psych.093008.100314

McFadyen, R. G., \& Thomas, J. P. (1997). Economic and psychological models of job search behavior of the unemployed. Human Relations, 50, 1461-1484. http://dx.doi.org/10.1177/001872679705001201

Melloy, R. C., Liu, S., Grandey, A. A., \& Shi, J. (2018). Overcoming emotional and attentional obstacles: A dynamic multi-level model of goal maintenance for job seekers. Journal of Vocational Behavior, 108, 92-107.

https://doi.org/10.1016/j.jvb.2018.06.009

Okay-Somerville, B., \& Scholarios, D. (2021). Focused for some, exploratory for others: Job search strategies and successful university-to-work transitions in the context of labor market ambiguity. Journal of Career Development. Advance online publication. https://doi.org/10.1177/08948453211016058

Pinquart, M., Juang, L. P., \& Silbereisen, R. K. (2003). Self- efficacy and successful schoolto-work transition: A longitudinal study. Journal of Vocational Behavior, 63, 329346. http://doi.org/10.1016/ S0001- 8791(02)00031- 3

Rosseel, Y. (2012). Lavaan: An R Package for Structural Equation Modeling. Journal of 
Statistical Software, 48, 1-36. https://doi.org/10.18637/jss.v048.i02

Saks, A. M. (2018). Job search and the school-to-work transition. In U.-C. Klehe \& E. A. J. van Hooft (Eds.), The Oxford handbook of job loss and job search (pp. 379-400). Oxford University Press. http://dx.doi.org/10.1093/oxfordhb/9780199764921.013.008

Saks, A. M., \& Ashforth, B. E. (2002). Is job search related to employment quality? It all depends on fit. Journal of Applied Psychology, 87, 646-654. https://doi.org/10.1037//0021-9010.87.4.646

Saks, A. M., Zikic, J., \& Koen, J. (2015). Job search self-efficacy: reconceptualizing the construct and its measurement. Journal of Vocational Behavior, 86, 104-114. https://doi.org/10.1016/j.jvb.2014.11.007

Savickas, M. L., \& Porfeli, E. J. (2012). Career Adapt-Abilities Scale: Construction, reliability, and measurement equivalence across 13 countries. Journal of Vocational Behavior, 80, 661-673. https://doi.org/10.1016/j.jvb.2012.01.011

Stremersch, J., \& Van Hoye, G. (2020). Searching hard versus searching smart: The role of search process quality in an internship context. International Journal of Selection and Assessment, 28, 31-44. https://doi.org/10.1111/ijsa.12274

Sun, S., Song, Z., \& Lim, V. K. G. (2013). Dynamics of the job search process: Developing and testing a mediated moderation model. Journal of Applied Psychology, 98, 771784. https://doi.org/10.1037/a0033606

Swanson, J. L., Daniels, K. K., \& Tokar, D. M. (1996). Assessing perceptions of careerrelated barriers: The Career Barriers Inventory. Journal of Career Assessment, 4, 219 244. https://doi.org/10.1177/106907279600400207

Turban, D. B., Stevens, C. K., \& Lee, F. K. (2009). Effects of conscientiousness and extraversion on new labor market entrants' job search: The mediating role of metacognitive activities and positive emotions. Personnel Psychology, 62, 553-573. 
https://doi.org/10.1111/j.1744-6570.2009.01148.x

van der Horst, A. C., Klehe, U.-C., \& van der Heijden, B. I. J. M. (2017). Adapting to a looming career transition: How age and core individual differences interact. Journal of Vocational Behavior, 99, 132-145. https://doi.org/10.1016/j.jvb.2016.12.006

Van Hooft, E.A.J., Born, M.Ph., Taris, T.W., Van der Flier, H., \& Blonk, R. W. B. (2004). Predictors of job search behavior among employed and unemployed people. Personnel Psychology, 57, 25-59. https://doi.org/10.1111/j.1744-6570.2004.tb02483.x

Van Hooft, E. A. J., Born, M. P., Taris, T. W., van der Flier, H., \& Blonk, R. W. B. (2005). Bridging the gap between intentions and behavior: Implementation intentions, action control, and procrastination. Journal of Vocational Behavior, 66, 238-256. https://doi.org/10.1016/j.jvb.2004.10.003

Van Hooft, E. A. J., Kammeyer-Mueller, J. D., Wanberg, C. R., Kanfer, R., \& Basbug, G. (2021). Job search and employment success: A quantitative review and future research agenda. Journal of Applied Psychology, 106, 674-713. https://doi.org/10.1037/ap10000675

Van Hooft, E. A. J., Wanberg, C. R., \& Van Hoye, G. (2013). Moving beyond job search quantity: Towards a conceptualization and self-regulatory framework of job search quality. Organizational Psychology Review, 3, 3-40. https://doi.org/10.1177/2041386612456033

Van Hoye, G. (2018). Job search behavior as a multidimensional construct: A review of different job search behaviors and sources. In U. C. Klehe \& E. A. J. Van Hooft (Eds.), The Oxford handbook of job loss and job search (pp. 259-274). Oxford University Press. https://doi.org/10.1093/oxfordhb/9780199764921.013.009 Van Ryn, M., \& Vinokur, A. D. (1992). How did it work? An examination of the mechanisms through which an intervention for the unemployed promoted job-search behavior. 
American Journal of Community Psychology, 20(5), 577-597. https://doi.org/10.1007/BF00941773

VDAB. (2020). Arvastat [Open data]. Retrieved from https://arvastat.vdab.be/

Vinokur, A., \& Caplan, R. D. (1987). Attitudes and social support: Determinants of jobseeking behavior and well-being among the unemployed. Journal of Applied Social Psychology, 17, 1007-1024. https://doi.org/10.1111/j.1559-1816.1987.tb02345.x

Wanberg, C. R., Ali, A. A., \& Csillag, B. (2020). Job seeking: The process and experience of looking for a job. Annual Review of Organizational Psychology and Organizational Behavior, 7, 315-337. https://doi.org/10.1146/annurev-orgpsych-012119-044939

Wanberg, C. R., Basbug, G., Van Hooft, E.A.J., \& Samtani, A. (2012). Navigating the black hole: Explicating layers of job search context and adaptational responses. Personnel Psychology, 65, 887-926. https://10.1111/peps.12005

Wanberg, C. R., Hough, L. M., \& Song, Z. (2002). Predictive validity of a multidisciplinary model of reemployment success. Journal of Applied Psychology, 87, 1100-1120. https://doi.org/10.1037/0021-9010.87.6.1100

Zikic, J., \& Klehe, U.-C. (2006). Job loss as a blessing in disguise: The role of career exploration and career planning in predicting reemployment quality. Journal of Vocational Behavior, 69, 391-401. https://doi.org/10.1016/j.jvb.2006.05.007

Zikic, J., \& Saks A. M. (2009). Job search and social cognitive theory: The role of careerrelevant activities. Journal of Vocational Behavior, 74, 117-127. https://doi.org/10.1016/j.jvb.2008.11.001

Zimmerman, B. J. (2000). Attaining self-regulation: A social cognitive perspective. In M. Boekaerts, P. R. Pintrich, \& M. Zeidner (Eds.), Handbook of self-regulation (pp. 1339). Academic Press. https://doi.org/10.1016/B978-012109890-2/50031-7 
Table 1

Items and Standardized Factor Loadings of the Job Search Quality Dimensions

\begin{tabular}{cccc}
\hline $\begin{array}{c}\text { Goal } \\
\text { establishment }\end{array}$ & Planning & $\begin{array}{c}\text { Goal } \\
\text { striving }\end{array}$ & Reflection \\
\hline
\end{tabular}

I set goals concerning the job I wanted to do

In my job search, I knew what my main goals

were

I had a clear idea of the type of job I was looking

for

I knew in which domain I wanted to work

I developed a coherent plan about how, when,

and where I would search for a job

I knew well how I would collect information

about jobs

I knew exactly how I would tackle the search for

a job

I set deadlines for myself in my search for a job

I persisted to reach my goal during my search for

a job

I translated my job search plans into concrete actions

I persevered in my search for a job, despite possible setbacks

I made sure I did not get distracted while looking for a job

I tried to learn something out of every application or contact with an organization for a job

After every contact with an organization

subsequent performance

I thought about how I could look for a job in even better ways

$N=255$. 
Table 2

Means, Standard Deviations, Internal Consistencies, and Correlations of Study Variables

\begin{tabular}{|c|c|c|c|c|c|c|c|c|c|c|c|c|c|c|c|}
\hline Variable & $M$ & $S D$ & 1 & 2 & 3 & 4 & 5 & 6 & 7 & 8 & 9 & 10 & 11 & 12 & 13 \\
\hline \multicolumn{16}{|l|}{ Time 1 variables } \\
\hline $1 \operatorname{Sex}^{\mathrm{a}}$ & 0.78 & 0.42 & - & & & & & & & & & & & & \\
\hline 2 Age & 22.91 & 2.12 & -.08 & - & & & & & & & & & & & \\
\hline 3 Education $^{\mathrm{b}}$ & 0.72 & 0.45 & -.08 & $.16^{* *}$ & - & & & & & & & & & & \\
\hline 4 Job search self-efficacy & 3.50 & 0.76 & -.09 & .08 & .00 & $(.82)$ & & & & & & & & & \\
\hline 5 Perceived labor market demand & 3.37 & 0.98 & $-.20 * *$ & .04 & .03 & $.16^{*}$ & $(.87)$ & & & & & & & & \\
\hline 6 Conscientiousness & 3.59 & 0.56 & $.24 * *$ & .03 & -.00 & $.37 * *$ & -.01 & $(.83)$ & & & & & & & \\
\hline 7 Social support & 4.11 & 0.66 & $.17 * *$ & -.03 & .05 & $.30 * *$ & $.21 * *$ & $.36 * *$ & $(.84)$ & & & & & & \\
\hline \multicolumn{16}{|l|}{ Time 2 variables } \\
\hline 8 Goal establishment & 3.67 & 0.82 & .04 & $.13^{*}$ & -.10 & $.27 * *$ & .01 & $.26 * *$ & $.20 * *$ & $(.84)$ & & & & & \\
\hline 9 Planning & 2.69 & 0.83 & $.14^{*}$ & .11 & -.11 & $.25 * *$ & .08 & $.24 * *$ & $.20 * *$ & $.49 * *$ & $(.81)$ & & & & \\
\hline 10 Goal striving & 3.23 & 0.91 & .10 & $.13^{*}$ & -.03 & $.26^{* *}$ & .07 & .31 & $.22 * *$ & $.62 * *$ & $.54 * *$ & $(.89)$ & & & \\
\hline 11 Reflection & 3.65 & 0.85 & .08 & .05 & .05 & $.27 * *$ & -.00 & $.25 * *$ & $.23 * *$ & $.61 * *$ & $.44 * *$ & $.67 * *$ & $(.87)$ & & \\
\hline \multicolumn{16}{|l|}{ Time 3 variables } \\
\hline 12 Job attainment $\mathrm{c}^{\mathrm{c}}$ & 0.77 & 0.42 & .09 & .01 & -.03 & $.14^{*}$ & -.06 & $.19 * *$ & .10 & $.38 * *$ & $.19 * *$ & $.45^{* *}$ & $.32 * *$ & - & \\
\hline 13 Perceived fit & 3.95 & 0.87 & .11 & -.03 & -.14 & .09 & .10 & .11 & $.18^{*}$ & $.20 * *$ & .09 & .08 & .04 & $\mathrm{~d}$ & $(.80)$ \\
\hline
\end{tabular}

13 Perceived fit

Reliability coefficients are shown in parentheses along the diagonal of the table.

${ }^{\mathrm{a}}$ Categories include $0=$ male $; 1=$ female. ${ }^{\mathrm{b}} 0=$ vocational college, $1=$ university. ${ }^{\mathrm{c}} 0=$ no, $1=$ yes.

${ }^{\mathrm{d}}$ Cannot be computed because at least one of the variables is constant (i.e., only those who attained a job at Time 3 could provide this information).

$* p<.05 ; * * p<.01$ 
Figure 1.

Hypothesized Model.

\section{Proximal antecedents}

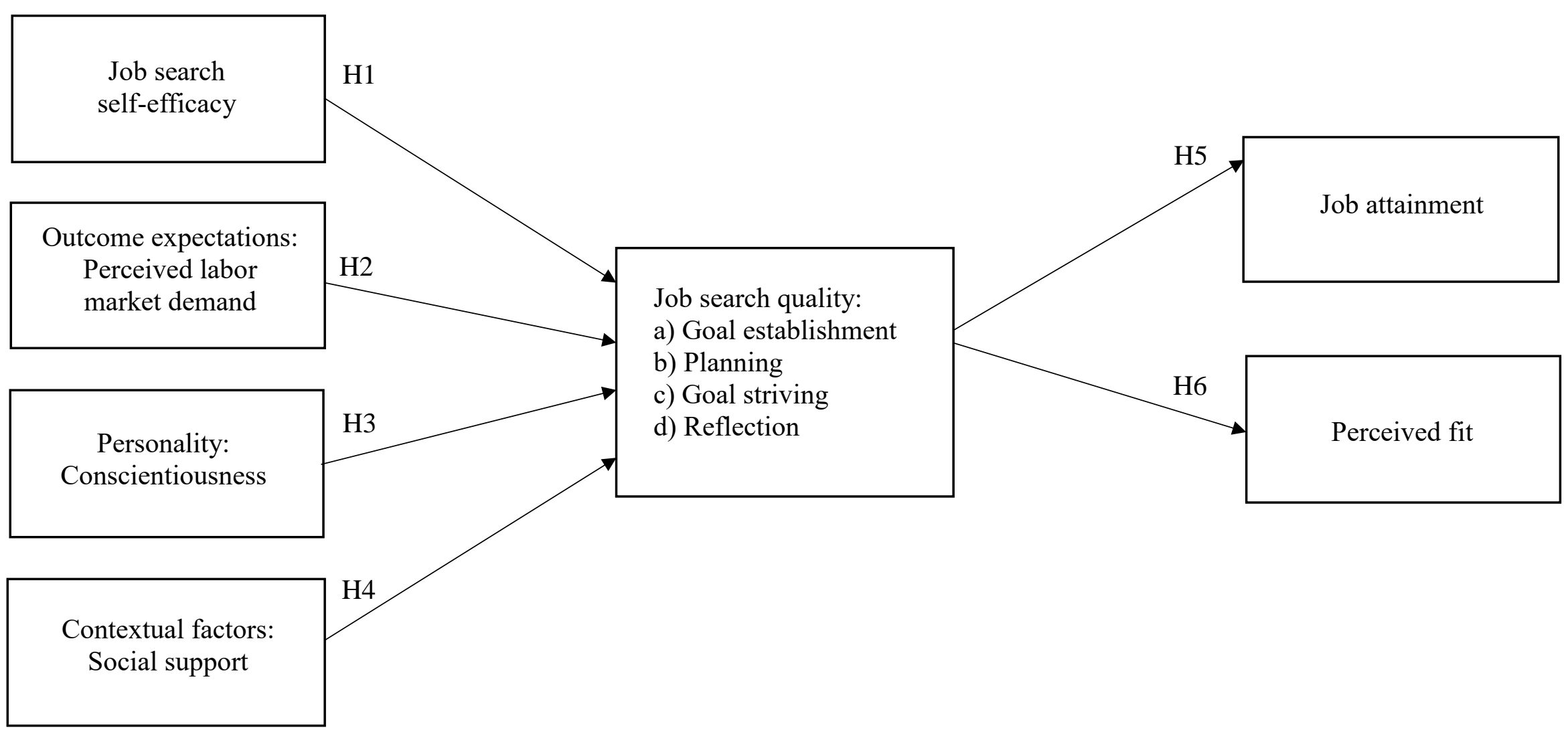


Figure 2.

Standardized Path Coefficients For the Hypothesized Model for Job Attainment.

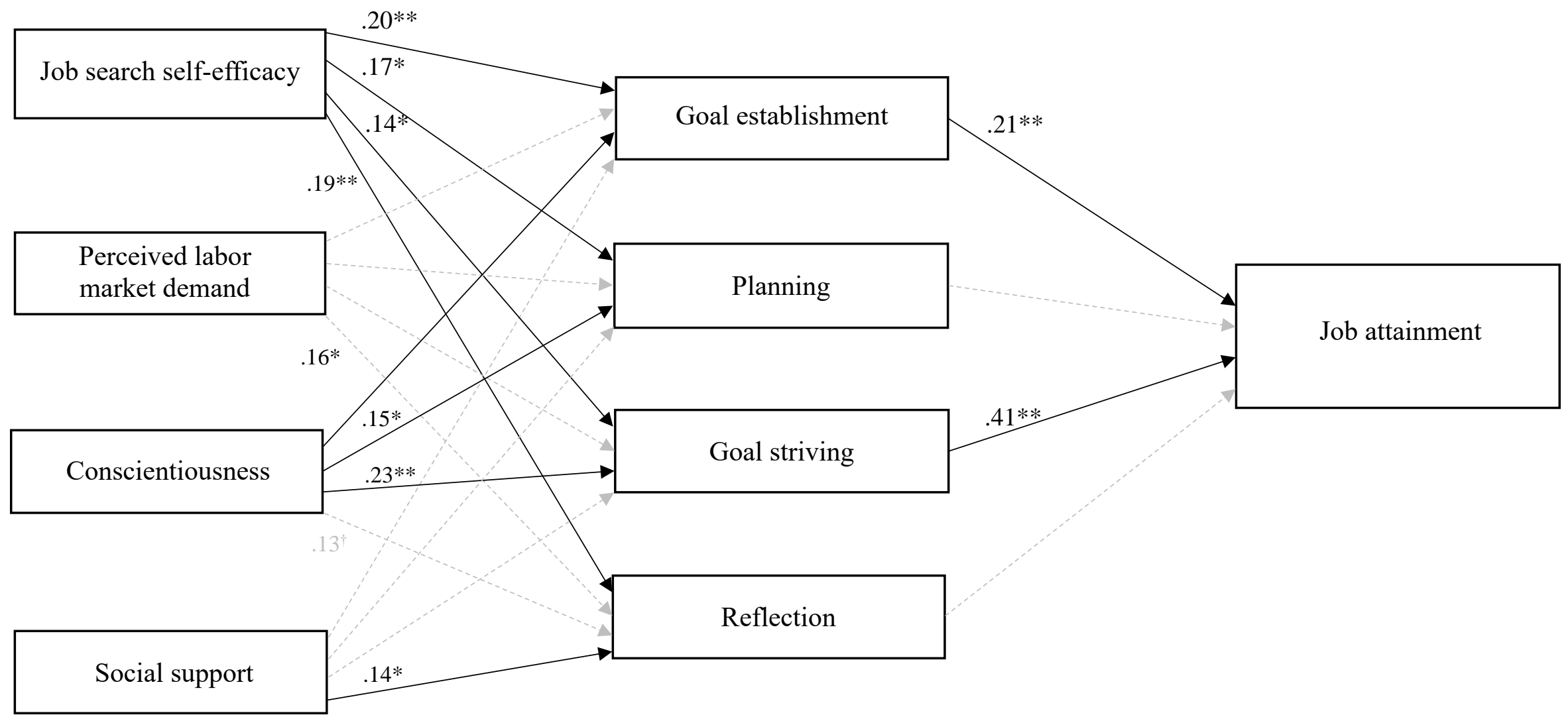

Note. $N=255$. Dashed lines represent nonsignificant paths. ${ }^{\dagger} p<.10,{ }^{*} p<.05, * * p<.01$. We controlled for age, sex, and education in the prediction of job attainment, but none of these paths were significant. Covariation was allowed between the proximal antecedents, between the job search quality dimensions, and between the control variables. 
Figure 3.

Standardized Path Coefficients For the Hypothesized Model for Perceived Fit

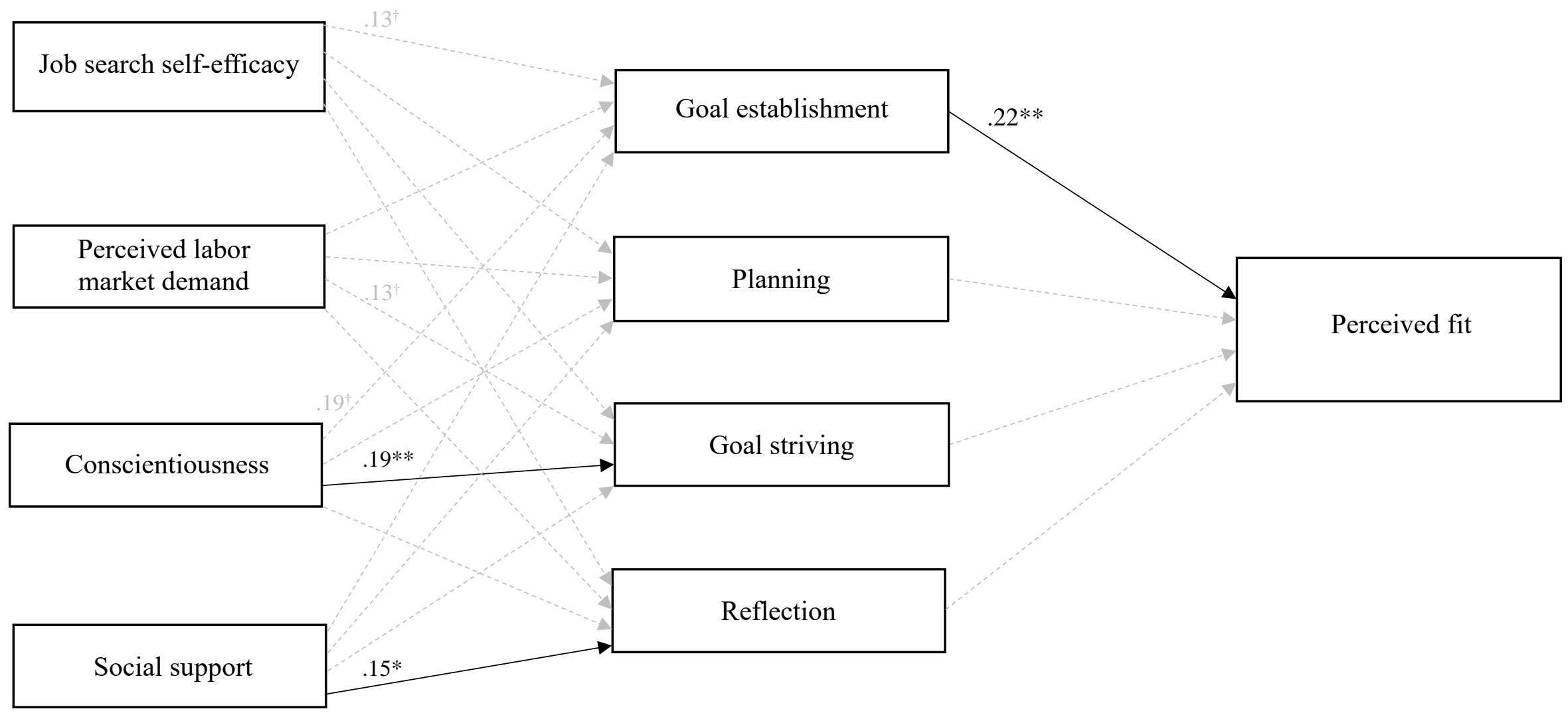

Note. $N=196$. Dashed lines represent nonsignificant paths. ${ }^{* *} p<.01,{ }^{*} p<.05,{ }^{\dagger} p<.10$. We controlled for age, sex, and education in the prediction of perceived fit, but none of these paths were significant. Covariation was allowed between the proximal antecedents, between the job search quality dimensions, and between the control variables. 